SHS Web of Conferences 6, 02014 (2014)

DOI: $10.1051 /$ shsconf / 20140602014

(C) Owned by the authors, published by EDP Sciences, 2014

\title{
The Future of the Migrant Workers: the Issue of Pensioning of the Retired Migrant Workers
}

\author{
Liu Boxia
}

Institute of Economic Research, Gansu Academy of Social Sciences, 730070 Gansu Lanzhou, China

\begin{abstract}
The first generation migrant workers contributed a lot to the construction of the cities with the lowest wages and the hardest work. On the other hand, due to flaws in the current social insurance systems, unclear responsibility of enterprises, insufficient understanding of the migrant workers themselves, there appear the dilemma that the cities refuse to care for migrant workers while the countryside cannot undertake the task and the traditional family and land-supporting model also fails to do so. And this has become an urgent problem faced the whole society. This paper, by analyzing the predicament and the issues of the care service of the retired migrant workers, presents solutions such as bettering the insurance system, quickening the law making, and popularizing the idea of responsibilities and consciousness of the enterprises and the farmer workers. It also calls for a power financial support from the government, and a way to unite the transitional system of the insurance policies, with strict supervision and management to protect the lawful interest of the migrant workers.
\end{abstract}

Keywords. migrant workers; pensioning of the retired; social security

The migrant workers appeared to be a special group during the system changes and social transformation of our country in 1990s, and they especially refer to the workers that work in the cities but having rural household, and at the same time possess two identities of farmer and worker. The appearance of migrant workers increases their own income, boosts the rural development and contributes a lot to the economic development of the cities, so they become the primary human resource for industrialization, urbanization and modernization of our country. However, the issue of their pensioning is still unresolved. Currently, this migrant workers generation faces its aging problem which leads them to be in a state of "unwanted and neglected", so their rights and interests are not well protected. According to the statistics of media, the number of "elder" migrant workers exceeding 50 years old has hit 36 million. The experts confirm that the pensioning problem incurred after "retirement" of the first migrant workers generation will be increasingly obvious, and 30 years of the accumulative welfare arrears issue will intensively break out within 5 years. Therefore, the rights and interests maintenance of endowment insurance for migrant workers has been a hot issue and difficulty in the recent years of domestic society.

\section{The difficulty of pensioning of migrant workers}

1) The dilemma is that the cities refuse to care for migrant workers while the countryside cannot undertake the task. Due to their special identities of "being or not being farmers and workers at the

This is an Open Access article distributed under the terms of the Creative Commons Attribution License 2.0, which permits unrestricted use, distribution, and reproduction in any medium, provided the original work is properly cited. 
same time", they are always put in a marginalized group in a dilemma. Therefore, they are excluded from the cities and rural endowment insurance system.

2) Family supporting model is weakening. Due to the low labor income that fails to achieve the pensioning accumulation expectations, and as the one-child policy is implemented, more and more Four-two-one family structures cannot independently undertake the pensioning task, which leads the traditional "raising children to provide for old age" model to be less dependable and urgently calls for social endowment insurance to take more responsibilities.

3) Land-supporting model faces challenges. Due to the low income, if they lose their work ability, it will be generally hard for them to survive in the cities, or due to their sentimental attachment to homeland, even though they come back to countryside, it'll still be hard for them to live. Currently for most rural areas, the number of people is more than that of lands, and the limited land resources are increasingly consumed by the development of urbanization, so living totally by the lands appears to be very difficult, let alone to be supported by the lands.

4) "New agricultural insurance" cannot undertake the task. As the saying goes, "For elderly, only silk can make them warm, and only meat can let them full", even though they come back to countryside and join "new agricultural insurance", their monthly basic pensions from new agricultural insurance income of 55yuan can just afford a few pounds of meat. So how could the elderly live on this insurance for just one month?

These issues are unfavorable to the construction of harmonious society and unified labor market, as well as in contradiction to basic principles of market sharing, which has brought some negative effects to some extent. Therefore, as this first migrant workers generation generally steps to the old age, the pensioning issue must be placed on the agenda as soon as possible, and the pensioning system concomitant reforms shall be performed to provide a more dependable pensioning welfare for the majority of migrant workers, aiming at creating for them a brighter and happier future.

\section{The issue in the pensioning of migrant workers and its reason analysis.}

To solve the problem of pensioning, we shall adopt a few ways, but in which the main measure is to incorporate the migrant workers into the social insurance system. Currently, the issue in the pensioning of migrant workers is: low insurance participation rate and high insurance surrendering rate. According to the data, as of September, 2012, the migrant workers in China that participate in the urban worker basic endowment insurance account only for $17.8 \%$ (based on the total number of migrant workers in China: 250 million), which is just $2 \%$ higher than that in 2008. One report shows that in some areas of migrant-worker-concentrated Guangdong Province, the insurance surrendering rate reaches up to over 95\%. Approximately more than 500 thousand migrant workers have participated in the endowment insurance, but in which the insurance surrendering rate hits over 120 thousand annually. What's worse, there were more than 600 migrant workers surrendering their insurance in Shajing social insurance station of Baoan District in Shenzhen within one day. According to the latest data reported by human resource and social insurance department in March 31, 2009, there are over 970 thousand migrant workers quiting the endowment insurance by the end of February in 2009. So what's behind this "low for one and high for the other" phenomenon?

\subsection{The priority is the inherent problem that lies in the endowment insurance system.}

Firstly, its system belongingness is unclear, and its standard is not unified. For the current practical situation, the endowment insurance established in some part of the areas for migrant workers mainly includes three types: (1) Independent migrant workers endowment insurance. Its policy is not related to other insurance types for migrant workers, and either to urban endowment insurance policy. It is an endowment insurance policy especially for "migrant workers". (2) Comprehensive migrant workers endowment insurance. It is an endowment insurance regulations and documents especially for migrant workers, not only in consideration of migrant workers' endowment insurance, but also relevant to 
healthcare, employment injury and other insurance types, and thus it formulates a comprehensive insurance policy. (3) Incorporation-type migrant workers endowment insurance. It incorporates migrant worker pensioning into the endowment insurance policy system, and distinguishes the migrant workers from the urban workers only in some part of provisions in relevant policies of urban workers endowment insurance; or incorporates the migrant workers pensioning into basic endowment insurance for urban and rural residents (new agricultural insurance). Some practices have been performed for the local migrant workers endowment insurance in the developed areas. However, there is no unified system standard in China.

Secondly, insurance participation policy is not well coordinated, and has a weak practical operability. The whole social insurance includes not only paying endowment insurance premium, but also the monthly payment such as unemployment, healthcare, maternity and employment injury insurance premium. The combination of five insurance premiums will be paid in accordance with $41.2 \%$ of wages base (enterprise paying $30.2 \%$, and individual paying $11 \%$ ), which is a heavy load for the enterprises and individuals, especially for migrant workers. Meanwhile, only accumulative payment for over 15 years can have them enjoy the retirement pay. But in consideration of the employment flexibility, the employment for migrant workers features poor stability and high mobility. So it is hard for them to work in one of the pooling regions or enterprises continuously for 15 years. If they cannot satisfy the conditions of collection, the migrant workers that participate in the pensioning pooling can only collect the payment in their individual accounts at a time, and the pooling account assets formed by enterprise payment will be contributed to the local government without compensation, which leads to the lack of positivity and initiative for most of the enterprises to pay endowment insurance premium for migrant workers. While as the migrant workers shift their working place, they can do nothing but to surrender the insurance, which make the enterprises and migrant workers both unwilling to pay the basic endowment insurance for urban workers.

Thirdly, the calculated age limit, payment method, treatment and benefits for the current endowment insurance is in compliance with the standard employment status in cities, so there are indeed some defects and irrationalities for the special group_-migrant workers. For instance, the endowment insurance payment is based on the average per capita wage for local workers. While currently in some western provinces and cities, the average yearly wages are much higher than the actual income for migrant workers. The currently formulated payment standard does not take into account the general low wage level for migrant workers that commonly work in labor-intensive industries. The payment is far beyond what the migrant workers can actually take. This is mainly why there're less urban workers surrendering insurance while more migrant workers doing so, and why migrant workers are worried about their aging but while refusing to pay insurance premium. Fourthly, The off-site transfer of endowment insurance is hard to perform. According to the formulations of current endowment insurance system, only the endowment insurance individual account, except for social pooling assets, can be transferred as workers flow into other areas. Given the seasonality and mobility for migrant workers, endowment insurance relations transfer shall be performed as the migrant workers participate in the insurance in one employing unit and then go to an another employing unit. But for migrant workers that flow from one province or city to another, they always cannot transfer and maintain their endowment insurance relations as they change jobs. Even though they can transfer the social insurance relations, the actual ones to perform this procedure are few, and insurance surrenderings are often occurred. Fifthly, the current social insurance system disconnects the rural areas to cities, which makes migrant workers fail to renew their insurance when they have paid social insurance premium in cities and returned to the residences, and thus cannot enjoy the relevant treatments. For that, the migrant workers couldn't support themselves even if they prefer participating in social insurance pooling, which to some extent prevent the migrant workers from positively participating in insurance.

\subsection{Migrant workers have limited abilities, lacking of self-cognitions.}

Firstly, the high employment and living pressure, as well as the lower income, make them have to take 
the living as priority, so that they cannot afford the endowment insurance premium in the future, and thus either formulate a further plan.

Secondly, the migrant workers possess poor cultural qualities and low cognition levels, which make them lack the understanding of the importance of endowment insurance. They see the endowment insurance as a thing of "appearing to be real but actually unpractical". Bearing " in the end things will mend" in mind, they have a poor awareness of insurance participation, and sometimes will think the surrender value as a surprising income when they just want to satisfy their temporary need.

Thirdly, they lack the knowledge of endowment insurance. As an investigation shows, the number of migrant workers that generally knows about the social endowment insurance is less than $20 \%$. Therefore, they don't fully trust the endowment insurance and couldn't understand the actual benefits from the social insurance that can be brought to them. They also suspect if they can obtain the pensions in a few years. Commonly thinking that "having one bird in hand is better than seeing hundreds of birds in the forest", they all have this kind of "possessing means real belonging" thought. $83.2 \%$ of the migrant workers are unwilling to pay the endowment insurance premium. The reasons are simple, because they think participating in insurance is like "deducting" their wages, which is obviously worse than putting money directly in their pockets. Fourthly, they lack legal knowledge, legal consciousness, self-protection abilities and right-protection awareness. To some right infringements as refusal of signing labor contracts, deduction and arrear of wages, and not paying social insurance premiums, they often choose to be tolerant, and don't take the legal weapon to maintain their legal rights and interests. This is one of the reasons why the promotion of endowment insurance system is not successful among migrant workers.

\subsection{Enterprises pursue the profit maximization and lose the social responsibilities.}

In consideration of their economic interests maximization, some enterprises are unwilling to pay endowment insurance premiums for workers. Objectively, it is caused by the single source of enterprise social insurance assets and the large financial gap. While the main reason that makes enterprise social insurance assets to be insufficient is caused by the single source of social insurance assets under the current systems. Subjectively, it is owing to the enterprises' pursuit of profit maximization and their loss of the social responsibilities. With the development of market economy, the private enterprises rise abruptly, occupying most of the markets. While the pursuit of profit maximization is an economic goal for private enterprises, as the profit is the life of enterprises. For this pursuit, the means performed is to reduce as much costs as possible to seize the markets by hook or crook. Under this source power of pursuing economic benefits, enterprises' social responsibilities have been lost, and most of them choose to avoid and act perfunctorily when facing problems of migrant workers insurance participations. As shown in the investigation, $80 \%$ of the enterprises are unwilling to pay endowment insurance premiums for migrant workers, and some of the enterprises even adopt various methods to dishonestly report the number of workers, just for the purpose of perfunctorily satisfying the compulsory requirements by government. For instance, the management in some enterprises put their own family members and relatives in the insurance participation list of workers in the enterprise. What's worse, some enterprises privately engrave the official seal of social insurance department, forge the insurance participation list and provide a false insurance participation bill, which make the enterprise insurance participation list of workers only an empty title. Some other enterprises fail to achieve "a fixed sum for a fixed purpose" and "specific account deposit" when returning the labor insurance funds. However, they choose to appropriate these funds for other purpose. They are mainly used for the enterprise management expenses, project construction assets and so on.

\subsection{The migrant workers social insurance right-protection cases are hard to be accepted due to legislation lag and slack law enforcement.}


Recently, our country and local government have formulated many policies and measures for the maintenance of rights and interests for migrant workers, but in the actual work, the legislation deficiency, slack law enforcement and poor administrative management are still existing, which lead to hard acceptance of migrant workers social insurance right-protection cases, and further weaken the functions of law with respect to maintaining rights and interests for labors. Owing to legislation lag, lack of administrative management and law enforcement for some relevant laws in our country, more of enterprises choose to escape from paying premiums of endowment insurance or other social insurance for migrant workers, and few of them will pay on their initiative.

\subsection{The imperfection of country's policy, and local governments' concern about the assets and their achievements make the endowment insurance for migrant workers severely lag.}

\section{The methods and advice on resolving issue of pensioning of migrant workers}

1) Perfecting endowment insurance system for migrant workers. (1)Establishing nationally unified and clear system regulations to perfect the nationwide insurance system and avoid the phenomenon of administering in their own way for regions. (2) Establishing an endowment insurance system suitable for features of migrant workers. Establishing an endowment insurance system suitable for features of migrant workers is based on the inherent problems in the system and the features of job instability, income instability and high mobility. Firstly, the household registration system and employment system shall be deeply reformed. The limitation between the rural household and non-rural household in middle-sized and small cities shall be totally eliminated, and the farmers shall be allowed to freely flow within the county territories in their residences. As long as the farmers have their fixed residences in cities, stable work and source of income, they shall be incorporated into the coverage of social insurance, and the social endowment insurance accounts shall be created for them, and further transferred as they shift their work areas. Meanwhile, the employing units shall be clearly required to pay endowment insurance premiums for migrant workers, further boost the employment system's reform, comprehensively promote the labor contract system and improve the labor supervision especially for industries and units that have more migrant workers to make sure that the employing unit shall sign a legal labor contract with migrant workers, and that the migrant workers can enjoy the social insurance treatments specified in the labor contract. Secondly, a flexible individual comprehensive account system shall be established. At first, a flexible single individual account shall be created. "One account for one person" system shall be performed nationwide. The migrant workers can take the accounts with them no matter where they will flow due to shift of working site, and this sole account can be used to participate in the insurance. Meanwhile, the migrant workers can alter the information, such as residence, on the internet, as well as transfer their endowment insurance relations among regions by job change certifications, and thus obtain the basic endowment insurance funds of social pooling of this season in the region of their new jobs. Secondly, a flexible payment method shall be established. One year may not be the age limit for payment accumulation, and the payment limit of individual accounts can be properly extended to one year or two years, which provide migrant workers with relatively sufficient time of capital turnover. Furthermore, the individual account may be flexibly used. The migrant workers shall be allowed to draw the money in their individual accounts in some special cases where, for example, they or their family members are in urgent need of money and some relevant certifications have been produced. In this case, the relevant departments shall positively assist them to draw a part or all of the funds. What's more, a classified payment system shall be performed. The employing units shall be allowed to pay social pooling endowment insurance premiums based on different payment ratios according to different work seniorities in the employing units for migrant workers. The longer their work seniorities are, the higher payment ratios will be, until the ratios reach the same level for urban workers when the work seniorities exceed a certain 
standard. A system that allows transfer among administrative regions shall be established. It is considered that the regulation which specifies 15 years payment as a premise of participation in endowment insurance could be changed to accumulated payment over 180 months as a premise of that, which means the years are converted to months. Meanwhile, a classified payment rate shall be set up. The migrant workers may make payment according to their own current income and different payment rates. They can pay in accordance with higher payment ratio when their incomes are higher; and with lower payment ratio when their incomes are lower. When they are retired, the weighted average of individual payment of migrant workers may be calculated, and they could collect the endowment insurance funds in compliance with the principle of "higher payment takes precedence". In the view of enterprises, the migrant workers may be classified according to their mobility and working time, and respectively determine their payment rates to establish differential payment rates. The payment rates for migrant workers that have lower mobility will be higher, and for ones that have higher mobility will be lower.

2) Boost the relevant legislations for pensioning of migrant workers. Government as a most important main body of responsibility shall enact relevant legal systems as soon as possible. There shall be a clear and unified regulation for detailed modes, payment and transferring patterns of social insurance participations for migrant workers, and it shall rise to the legal level.

3) Strengthen the educative promotion, and intensify the social endowment insurance consciousness and responsibilities for migrant workers and employing units. The government shall vigorously conduct promotions of endowment insurance for migrant workers, and hold a series of educative and lively activities to awake the migrant workers' social endowment insurance awareness. For that, the self-protection consciousness of migrant workers will be intensified, and while increasing their sense of identity for social endowment insurance. The relevant endowment insurance knowledge shall be positively promoted to migrant workers to acquaint them with the purpose, functions and meanings of endowment insurance our country establishes. Furthermore, the government shall let them know about the routes, ways of participating in endowment insurance and the collection of pensions. Additionally, the main enterprises shall be provided with relatively professional and systematic training to intensify their responsibilities, let them be aware that it is their duty to pay insurance premiums for migrant workers, for the purpose of making enterprises positively pay endowment insurance premiums for migrant workers. Through promotion and education, a social consensus shall be formed; It is not only the responsibility of the government that migrant workers' working sites belong to, but also of the local government and rural organizations that migrant workers' residences belong to, to solve the issue of pensioning of migrant workers;

4) The government shall increase the financial support. It shall take the financial responsibility of social endowment insurance for migrant workers and enact insurance policies of low age limit and low insurance that correspond to low payment of migrant workers. Based on reasonable rate adjustment and payment base, the government shall appropriately provide endowment insurance for migrant workers with subsidies. Meanwhile, it shall give tax preferences to enterprises that positively pay social insurance premiums for their workers, for the purpose of improving positivity of enterprises to participate in the endowment insurance.

5) Formulate methods of off-site transferring and renewal of nationwide unified endowment insurance relations for migrant workers. One of the methods is to establish nationwide endowment insurance funds for migrant workers. The merging of new agricultural insurance and endowment insurance for urban residents shall be performed as soon as possible to realize national pooling, for the purpose of letting migrant workers freely make payment and collecting pensions wherever they are as long as they hold the social insurance cards. The other method is to establish endowment insurance relations for migrant workers in their residences. Dynamic adjust the pensions. Connect the basic pensions of monthly 55yuan per capita to commodity price, and have it dynamically adjusted in accordance with price fluctuations to ensure the performance of minimum-guarantee functions of endowment insurance. Perfect the rural pensioning services. Based on providing five-guarantee and "three-no" elderly with insurance service, the extension, door-to-door or other services shall be provided to all the rural elderly. Meanwhile, the government shall encourage development of non-governmental pensioning organization and explore various pensioning services of, for example, 
support, nursing and healthcare types.

Intensify the supervision and management to practically maintain the legal rights of migrant workers.

\section{References}

1. Chen Liangqin. Brief Analysis on the Issue, Reason and Method of Endowment Insurance Participation for Migrant Workers in Building Industry — Taking Chansha city for example[J]. China Collective Economy,2012(8).

2. Zhang Xiaomei. The Issue and Method of Pensioning of Migrant Workers[J]. Journal of Yangtze University (Social Sciences), 2012 (11).

3. Zheng Wenyang. Analysis on the Issue and Method of Domestic Endowment Insurance for Migrant Workers [J]. Management, 2008 (10).

4. Wang Yong. Analysis on the Issue and Method of China Endowment Insurance System for Migrant Workers [J]. Basic Theory Discussion, 2011(4).

5. Qiu Xiaowu, Yusong. The Aging Difficulty the First Migrant Workers Generation Face: The Pensioning Issue will Intensively Break Out Within 5 Years [N]. Chongqing Kai County Morning Paper,2013-02-26.

6. Zhang Fengyi. Who Comes to Undertake the Task of Pensioning of the First Migrant Workers Generation [N], Xian Evening Paper, 2013-02-27.

7. Sunflower Insurance. Analysis on the Issue and Method of Endowment Insurance for Migrant Workers [N]. 2011-07-27.

8. Jiao Zongya.Brief Analysis on the Issue and Method of Endowment Insurance for Migrant Workers. 2007- 9-10.

9. Hujie,Li Chaohui. Discussion of the Issue and Advice of Establishment of Endowment Insurance System for Migrant Workers [R]. 2012.0 